\title{
PARADOXOS DA AUTONOMIA PRECÁRIA: LEGISLAÇÃO COOPERATIVISTA E TRABALHO
}

\section{PARADOXES OF PRECARIOUS AUTONOMY: COOPERATIVIST LEGISLATION AND LABOUR}

\author{
José Antonio Peres Gediel* \\ Lawrence Estivalet de Mello**
}

\begin{abstract}
RESUMO
O presente artigo tem como objeto a análise da forma como se constitui uma autonomia precária, no âmbito do trabalho autônomo no Brasil, e sua permanência com a renovação legislativa do cooperativismo. Divide-se, para tanto, em três momentos. No primeiro, apresenta a origem da Lei n. 5.764/1971 e a diferença entre cooperativismo tradicional e cooperativismo popular. No segundo, contextualiza a ampliação do trabalho autônomo de baixa renda às demandas do cooperativismo popular. No terceiro, enfim, analisa a nova produção legislativa do cooperativismo no Brasil, por meio do PLS n. 03/2007 e da Lei n. 12.690/2012, com efeitos sobre o trabalho autônomo. Cuida-se de exame bibliográfico que possibilita a análise das descontinuidades e permanências que ocorrem com a renovação legislativa do trabalho cooperado no Brasil.
\end{abstract}

\section{PALAVRAS-CHAVE}

Trabalho autônomo. Legislação cooperativa. Autonomia precária.

\begin{abstract}
The object of this article is an analysis of the way in which a precarious autonomy is constituted in the scope of autonomous work in Brazil, and its permanence with the legislative renewal of cooperative labour. The article is therefore divided into three part. First, the origins of Law n. 5.764/1971 as well as the difference between traditional and popular cooperativism are presented. Second, it contextualizes the widening of the low-income autonomous work in relation to the demands of popular cooperativism. Third and lastly, the new cooperativist legal framework in Brazil is analyzed through Bill n. 03/2007, proposed in the Senate, and through Law n. 12.690/2012. The article includes a bibliographical review that enables the analysis of the discontinuities and constancies that occur with the legislative renewal of cooperative labour in Brazil.
\end{abstract}

\footnotetext{
* Professor Titular da Universidade Federal do Paraná. Vinculado ao Departamento de Direito Civil e Processual Civil, do Setor de Ciências Jurídicas, desenvolve atividades docentes no curso de graduação e no Programa de Pós-Graduação em Direito (PPGD/UFPR, Curitiba, PR, Brasil), no qual exerceu a função de coordenador, por duas vezes, no período de 2009 a 2012. É Doutor e Mestre em Direito pela UFPR e graduado em Direito pela Universidade Federal do Rio Grande do Sul (UFRGS). Realizou pós-doutorado na Universidade de Montréal, Canadá. Exerceu o cargo de Procurador do Estado do Paraná desde 1993. É coordenador dos grupos de pesquisa: Direitos Humanos, Democracia e Conflitos Sociais e Direito Cooperativo e Cidadania, cadastrados no CNPQ e vinculados ao PPGD/UFPR. E-mail: jagediel@gmail.com

** Mestre em Direito pelo PPGD/UFPR (Programa de Pós-Graduação em Direito), na área de concentração Direitos Humanos e Democracia, com bolsa CNPq-GM. Professor do curso de Direito da UNIGUAÇU (Faculdades Integradas do Vale do Iguaçu). Advogado inscrito na OAB/PR. Pesquisador e Secretário do Núcleo de Pesquisa Direito Cooperativo e Cidadania, vinculado ao PPGD/UFPR (Curitiba, PR, Brasil).E-mail: lawestivalet@gmail.com
} 


\section{KEYWORDS}

Autonomous work. Cooperative legislation. Precarious autonomy.

\section{INTRODUÇÃO}

O principal marco jurídico do cooperativismo, no Brasil, é a Lei n. 5.764/1971. Desenvolveram-se, sob seu fundamento, o cooperativismo tradicional e o cooperativismo popular, bem como intensa disputa judicial acerca das "cooperfraudes” ou "coopergatos”", modalidade jurídica utilizada para a precarização do trabalho.

Nos últimos anos, por conta de demanda do movimento cooperativista e como síntese de suas tensões, desenvolveram-se iniciativas para sua renovação legislativa, em duas frentes. A primeira corresponde à regulamentação das cooperativas de trabalho e se materializa na Lei n. 12.690/2012. A segunda concerne ao marco geral do cooperativismo, em suposta busca de superação da legislação da ditadura civil-militar, no recentemente aprovado PLS n. 03/2007.

O presente artigo investiga as consequências da renovação legislativa, do ponto de vista do cooperativismo popular e do processo de precarização do trabalho no Brasil (ANTUNES, 2010; BRAGA, 2012; OLIVEIRA, 2013). Sinaliza a instituição de uma “autonomia precária”2, no âmbito do trabalho autônomo, bem como de permanências conservadoras que obstaculizam o crescimento do cooperativismo popular, mesmo com a instituição do novo marco geral legislativo.

Para tanto, apresenta-se o surgimento da legislação cooperativista e dimensionam-se o cooperativismo tradicional e popular (seção 1), para, na sequência, sistematizar as dificuldades do cooperativismo popular (seção 2), com o fito de, por fim, analisar o sentido das descontinuidades realizadas por meio da Lei n. 12.690/2012 e do PLS n. 03/2007 (seção 3).

\footnotetext{
1 "Esta é uma das origens do surto de cooperativas de trabalho. Empresas criam cooperativas de trabalho, com seus estatutos e demais apanágios legais, as registram devidamente e depois mandam seus empregados se tornarem membros delas, sob pena de ficar sem trabalho. Os empregados são demitidos, muitas vezes de forma regular, e continuam a trabalhar como antes, ganhando o mesmo salário direto, mas sem o usufruto dos demais direitos trabalhistas. Estas são as falsas cooperativas também conhecidas como cooperfraudes e outros epítetos. São cooperativas apenas no nome, arapucas especialmente criadas para espoliar os trabalhadores forçados a se inscrever nelas" (SINGER, 2004, grifos do autor).

2 A autonomia, no sentido kantiano clássico, consiste "no fato de o sujeito se dar a si a própria lei da conduta" (LUDWIG, 2011, p. 50). Corresponde, portanto, a uma refutação da fundamentação heterônoma da vontade. No lugar de "interesses", "felicidade", "prazer", o sujeito age em nome da "boa vontade”. Sem dúvida, não é essa boa vontade, autolegislada, que motiva o trabalho autônomo no Brasil. Ainda assim, é com essa aparência que se apresenta a autonomia no seu sentido tradicional, que faz nascer o dito trabalho autônomo. Diferentes críticas podem ser apresentadas à noção de autonomia kantiana, em especial pelo formalismo e idealismo com que o autor fundamenta sua ética. Para uma crítica marxista da ética kantiana, veja-se Mészáros (2011).
} 


\section{A LEI N. 5.764/1971, O COOPERATIVISMO TRADICIONAL E O COOPERATIVISMO POPULAR}

Em 2010, existiam 24.128 cooperativas no Brasil, número que expressa crescimento de 6,4\% se comparado com o de 2006. Apenas em exportações, as cooperativas foram responsáveis por movimentação superior a seis bilhões de dólares em 2013. O grupo hegemônico no cooperativismo brasileiro é o das cooperativas agroindustriais, vinculadas à exportação de commodities no setor do agronegócio (ARAUJO, 2014, p. 28 et seq.).

O número total de Empreendimentos de Economia Solidária (EES), no Primeiro Mapeamento do $\mathrm{SIES}^{3}$, era de 21.859, entre cooperativas, associações e grupos informais. No Segundo Mapeamento, divulgado em 2013, foram registrados 19.708 empreendimentos, o que representa uma redução de 2.151 grupos. Nesse segundo mapeamento, registra-se o total de sócios em EES como mais de um milhão de pessoas (1.423.631).

O montante financeiro ou numérico não traduz o que seja o cooperativismo no Brasil, mas fornece importantes indícios de dimensionamento do fenômeno. Não por acaso, a forma jurídica cooperativa abriga vultosas movimentações financeiras e esforçadas experiências populares, estas com dificuldades. Há uma diferença de natureza entre elas, sobre a qual breve análise do histórico apresenta contrastes e expectativas.

Em 1907, pela primeira vez as cooperativas eram citadas em um marco jurídico no Brasil. Era o Decreto n. 1.637, que as classificava como uma espécie de sociedade comercial (KRUPPA; GONÇALVES; MACDONALD, 2012, p. 17). Em 1932, surgia o primeiro marco jurídico consistente sobre o tema. Tratava-se do Decreto n. 22.239/1932 (OPUSZKA, 2012, p. 52), hoje revogado.

Ainda em vigor e com grande importância história, tem-se a Lei n. 5.764/1971. Como destaca Eduardo Faria Silva, há uma relação direta entre o sistema cooperativista nacional e as diretrizes da Revolução Verde e da Aliança para o Progresso, no contexto da política econômica do regime civil-militar no Brasil (SILVA, 2011, p. 150). A legislação cooperativista data de 1971, alguns anos após o golpe militar. Essa conexão é esclarecedora para a identificação do sentido histórico do cooperativismo.

\footnotetext{
${ }^{3}$ Em 2003 foi criada a Secretaria Nacional de Economia Solidária (SENAES), no âmbito do Ministério do Trabalho e Emprego (MTE). Entre suas atribuições, está a promoção de pesquisas e estudos que contribuam para viabilizar e coordenar as atividades de economia solidária. Por esse motivo, foi criado o Sistema de Informações em Economia Solidária (SIES), que realiza o mapeamento nacional dos empreendimentos, entidades de apoio, assessoria e fomento à economia solidária. Como resultado do Primeiro Mapeamento Nacional, foi elaborado e divulgado o "Atlas da Economia Solidária” (BRASIL, 2008). Como resultado do Segundo Mapeamento Nacional, foi elaborado e divulgado o “Atlas Digital da Economia Solidária” (BRASIL, 2013).
} 
Destaca-se, desse modo, que a legislação cooperativa e a fundação do cooperativismo tradicional não surgem, por acaso, no período da ditadura civil-militar. Surgem em consonância à modernização conservadora da agricultura, que encontra na OCB (Organização das Cooperativas Brasileiras) uma grande aliada, no plano dos aparelhos privados de hegemonia 4 .

A OCB é resultado da fusão entre a Aliança Brasileira de Cooperativas (ABCOP) e a União Nacional das Associações de Cooperativas (UNASCO), realizada em dois de dezembro de 1969. Sua ata de constituição apresenta três indícios de ligação às classes dominantes, conforme sistematização de Faria Silva, cuja expressão de poder era a ditadura civil-militar. O primeiro deles é que sua reunião de constituição foi convocada pelo então Ministro da Agricultura, Fernando Cirne Lima. O local da reunião, não por acaso, foi o gabinete do referido Ministro. O segundo é constituído pelos eixos de atuação da nova entidade. O pensamento cooperativista passa a ser representado pela OCB, que possui independência do Estado, todavia "colaborando franca e lealmente com as autoridades”. O terceiro indício, enfim, é a composição da mesa diretora dos trabalhos do IV Congresso, que constitui a OCB, em que estavam presentes comandantes, general, arcebispo, entre outros (SILVA, 2006, p. 68-69).

A própria $\mathrm{OCB}$, em publicação referente à sua história, menciona sua relação de franca colaboração com o governo civil-militar: "como a grande força das cooperativas estava no campo, passou a ser interessante para o Estado que o movimento [de constituição da OCB] se consolidasse e ajudasse o governo a realizar sua política econômica para o setor agrícola” (SILVA, 2006, p. 70).

O Marechal Presidente Emílio Garrastazu Médici é o responsável pela proposição da Política Nacional do Cooperativismo. Em 1971, encaminha à Câmara de Deputados a Mensagem n. 300, que acompanha a Exposição de Motivos n. 45, Projeto de Lei que viria a instituir o regime jurídico das cooperativas e outras providências. Era o nascimento da Lei n. 5.764/1971.

A Exposição de Motivos havia sido elaborada pelo Ministro da Agricultura. Situava a Política Nacional do Cooperativismo nos objetivos estabelecidos pelo governo à área rural. Buscava incorporá-la ao desenvolvimento nacional, com promessa de concessão de estímulos ao cooperativismo. Na ata da primeira reunião da Diretoria Provisória da OCB, realizada no gabinete de Antonio José Rodrigues Filho, Secretário de Agricultura de São Paulo e Presidente da OCB, verifica-se que o projeto de lei foi encaminhado após tratativas diretas entre o Ministro Cirne Lima e o Presidente da Diretoria Provisória da OCB.

\footnotetext{
${ }^{4}$ Aparelhos privados de hegemonia, no interior do marco teórico gramsciano, são os que exercem operações ideológicas na denominada "sociedade civil”, como partidos políticos, escolas, igrejas, mídia etc. Para uma interpretação brasileira do legado gramsciano, veja-se COUTINHO, 2011.
} 
Não por acaso, a Lei n. 5.674/1971 prevê a representação oficial do cooperativismo pela OCB (art. 105) e a obrigatoriedade de filiação das cooperativas à entidade (art. 107). O quadro de controle do movimento cooperativista, em comunhão ao modelo ditatorial, completa-se com os art. 17 e 18 da Lei, referentes ao arquivamento de documentação na Junta Comercial e à obtenção de personalidade jurídica por parte das cooperativas.

O projeto político que se materializa na referida Lei é considerado um divisor de águas pela OCB. Segundo publicação da entidade, é ele que viabiliza a OCB e moderniza as cooperativas na perspectiva do modelo empresarial, visando à sua expansão econômica e à adequação às exigências do desenvolvimento agrícola agroindustrial adotado pelo Estado (SILVA, 2006, p. 76).

Após quase duas décadas de vigência, o modelo proposto pela Lei n. 5.764/71 voltou a ser assunto de debate na Assembleia Nacional Constituinte. Conforme aponta Silva, os principais temas em debate foram o apoio e incentivo, educação, regime tributário e liberdade de constituição e funcionamento das cooperativas (SILVA, 2006, p. 86).

Sobre este último, relevante polêmica se instituiu. As tentativas da OCB foram de garantia de "um duplo movimento: a) externo - de autonomia plena da OCB perante o Estado; b) interno de submissão total das cooperativas somente à OCB” (SILVA, 2006, p. 87). Esse objetivo seria levado a efeito pela Frente Parlamentar do Cooperativismo (FRENCOOP). Em 1984, ela possuía 45 candidatos a senadores e deputados, eleitos com o apoio da OCB. "No transcorrer dos trabalhos da Constituinte os números aumentaram significativamente e chegaram a 217 parlamentares das mais variadas siglas partidárias” (SILVA, 2006, p. 88).

Como assinala Faria Silva, os efeitos das disposições constitucionais (em especial, o art. 5, incisos XVIII e XX), devidamente interpretadas pelos julgados que se seguiram à promulgação da CF/1988, escaparam às pretensões da OCB. Basicamente, rompe-se controle histórico e estabelecese liberdade de associação e organização das sociedades cooperativas. Passam a ser considerados inconstitucionais e revogados tacitamente os artigos 105 e 107 da Lei n. 5.764/1971 (SILVA, 2006, p. 91).

Seria ingênuo, no entanto, acreditar que o cooperativismo tradicional apenas perdeu com o período que se inicia após a Constituição Federal. Pelo contrário, é a década do neoliberalismo, da reestruturação produtiva, do transformismo das lutas sociais. Cresce, destarte, o desemprego, e, com ele, a construção do cooperativismo popular, como alternativa para produção de trabalho e renda. Gesta-se, igualmente, a modificação gerencial do Estado brasileiro e, com ela, novas formas de fortalecimento do cooperativismo tradicional. 
Do ponto de vista do cooperativismo tradicional, duas medidas são destacadas na sua busca por reestruturação. São elas: a instituição do SESCOOP (Serviço Nacional do Cooperativismo) e a proposta de nova Lei das Cooperativas (PL n. 171/1999, de autoria do Senador Osmar Dias). Ambas são realizadas ao final da década de 1990 - respectivamente, em 1998 e 1999, no contexto neoliberal.

O PL n. 171/1999 possuía quatro questões estruturais: “a) o ato cooperativo; b) a abertura do capital das cooperativas; c) a possibilidade de pessoas jurídicas de qualquer natureza associaremse às cooperativas; d) representatividade do sistema cooperativo permanecer com a OCB” (SILVA, 2006, p. 110).

Destaquem-se as intenções quanto ao ato cooperativo e quanto à abertura do capital. Aquele era tradicionalmente reconhecido como o realizado na relação entre cooperado e cooperativa ou na relação entre cooperativas, quando associadas, para a consecução dos seus objetivos sociais. Com o PL n. 171/1999, buscava-se a instrumentalização do sistema cooperativo, com vistas à evasão fiscal. Em seu art. 48, era estendida a imunidade tributária aos "negócios auxiliares” ou "meios indispensáveis” à consecução dos objetivos sociais da entidade. Assim, por exemplo, não incidiria tributação "sobre o lucro auferido por uma empresa que realizou ato com a cooperativa”, nem mesmo seriam recolhidas contribuições ao trabalhador, em eventual relação empregatícia mantida na entidade, tudo albergado nos “meios indispensáveis” à consecução dos objetivos sociais (SILVA, 2006, p. 112). Já a abertura do capital, prevista nos artigos 15, 17 e 58, prescrevia a possibilidade de pessoa jurídica de qualquer natureza associar-se a uma cooperativa. A cooperativa deixaria de ser uma sociedade de pessoas e passaria a ser uma sociedade de capitais. Por consequência, ter-se-ia a desvirtuação completa do ideário cooperativista 5 .

O SESCOOP, por outro lado, foi instituído mediante a Medida Provisória n. 1.715/1998 e o Decreto n. 3.017/1999, ambos do Presidente Fernando Henrique Cardoso. Seu objetivo é “organizar, administrar e executar, em todo território nacional, o ensino de formação profissional, desenvolvimento e promoção social do trabalhador em cooperativas e dos cooperados” (art. $8^{\circ}$ ). Possui personalidade jurídica de direito privado e Conselho Nacional próprio (art. $9^{\circ}$ ), além de diversas fontes de receita (art. $\left.10^{\circ}\right)$.

\footnotetext{
5 “A adoção dessas medidas acaba completamente com a construção originária do cooperativismo, acolhida até mesmo na Lei n. ${ }^{\circ}$ 5.764/71, de que as cooperativas são uma sociedade de pessoas e não de capital. A readequação proposta, mesmo que mantido o princípio de um voto por cabeça nas Assembléias Gerais, permitirá a ingerência completa, no cotidiano das cooperativas, das estruturas societárias que operam com uma lógica diversa. Ingenuidade ou dissimulação pensar, por exemplo, que a participação da Monsanto como detentora de Certificados de Aporte de Capital ou como associada da cooperativa não produza influência direta na condução das atividades da entidade e que seus interesses econômicos não se sobreponham aos interesses individuais ou coletivos dos cooperativados” (SILVA, 2006, p. 113).
} 
Os recursos do SESCOOP são um ponto importante para o entendimento do trabalho nas cooperativas tradicionais. Observe-se que sua principal fonte de recursos é a contribuição mensal compulsória dos empregados das cooperativas, recolhidas pela Previdência Social, no montante de 2,5\% sobre a remuneração dos trabalhadores (art. 10, I da MP). Admite-se e privilegia-se, portanto, o trabalho subordinado nas cooperativas, com objetivo de aumento da receita para a SESCOOP. Faria Silva cita tabela, oriunda de relatório de Comissão Parlamentar Mista de Inquérito (CPMI da Terra), cuja sistematização demonstra que “a OCB e o SESCOOP receberam dos cofres da União juntas, aproximadamente, R\$ 200.307 milhões [sic], entre janeiro de 1995 e outubro de 2005”6.

Não é apenas uma questão econômica, no entanto. Pode ser realizada uma série de questionamentos a respeito da compatibilização entre o estímulo ao trabalho subordinado e os princípios do cooperativismo ${ }^{7}$. Nessa senda, Silva conclui que as duas medidas - SESCOOP e PL n. 171/19998 - fizeram parte de uma readequação legislativa capitaneada pela OCB, que seguramente não visava a uma busca pelo ideário clássico do cooperativismo, mas sim à adaptação do cooperativismo à economia de mercado, neoliberal.

O cooperativismo, como afirmado ao começo da seção, encontra-se em franca ascensão. O número de cooperativas cresce, sua cifra de movimentação financeira também. Poder-se-ia relativizar a importância da OCB, visto que são filiadas a ela apenas 27,56\% das cooperativas no Brasil, número que demonstra ausência de legitimidade para representação única do movimento cooperativista (ARAUJO, 2014, p. 40). Porém, são relevantes os dados que conferem justificativa para a visibilidade e poderio da OCB. Em 2007, o “sistema” OCB movimentou R\$ 72 bilhões; em 2009, R\$ 88,5 bilhões; em 2012, apenas as cinco maiores cooperativas do Paraná totalizaram movimentação de R \$ 38,5 bilhões. Assim, “a expressão da OCB não está relacionada à legitimidade de representação do cooperativismo brasileiro como um todo, mas sim do mais rico” (ARAUJO, 2014, p. 42).

O “cooperativismo mais rico” utiliza-se, então, de uma figura formal (pessoa jurídica cooperativa) para uma atuação empresarial. O motivo é obtenção de vantagens, como “agregar

\footnotetext{
${ }^{6}$ Ver tabela em SILVA, 2006, p. 116. O texto original apresenta a cifra de "R\$ 200.307 milhões", mas verifica-se, na legenda correspondente, que o correto é “R\$200,307 milhões”.

7 “[...] questiona-se, inicialmente, se é condizente com os valores e princípios cooperativos a existência de trabalhadores contratados em cooperativas e, ainda, se é papel das entidades cooperativas prepará-los para o trabalho subordinado, ao invés de qualificá-los para a autogestão. Por outro viés, pergunta-se se é condizente com os valores e princípios cooperativos que o Serviço Nacional de Aprendizagem do Cooperativismo - SESCOOP seja financiado por contribuições oriundas do desconto previdenciário dos trabalhadores em cooperativas. Sob outro prisma, indaga-se se é condizente com os valores e princípios cooperativos que o Serviço Nacional de Aprendizagem do Cooperativismo SESCOOP seja presidido por uma entidade que representa a classe patronal” (SILVA, 2006, p. 118).

${ }^{8}$ Importa destacar que o referido projeto foi arquivado em 22 de janeiro de 2007 . Ainda assim, expressa as intenções do setor ligado à OCB na década de 1990. A disputa legislativa por novos projetos para a forma jurídica cooperativista prosseguiu, em que pese o arquivamento.
} 
vários pequenos produtores rurais como associados, bem como liberar as transações havidas com eles (comercialização da produção; venda de insumos; financiamento; etc.) de taxas tributárias” (ARAUJO, 2014, p. 37). Trata-se, com efeito, de uma firma-fraude.

Veja-se que o objetivo empresarial em nada condiz com o ideário cooperativista. Alguns autores relativizam, no entanto, a essencialidade dos princípios éticos no interior do ideário cooperativista, com priorização do elemento econômico. Mesmo na vertente conservadora do cooperativismo, todavia, prevalece o entendimento de convivência entre elemento econômico e elemento social, em configuração de duplicidade de intenções (ARAUJO, 2014, p. 88).

As opções hegemônicas no marco jurídico cooperativo são, ainda hoje, as do cooperativismo tradicional. Como contextualizado, a política operada pelo SESCOOP, controlado e gerido pela OCB, leva diretamente à precarização do trabalho por meio de cooperativas. É do interesse dos associados das cooperativas tradicionais o crescimento do SESCOOP. É também de seu interesse, portanto, impulsionar a existência de trabalho subordinado no interior das cooperativas. Com efeito, o cooperativismo brasileiro é “marcado pelas opções agrícola, na política de modernização do campo, e, posteriormente, neoliberal, valorizando as cooperativas empresariais, notadamente agrícolas” (ARAUJO, 2014, p. 88).

O cooperativismo popular cresce nesse mesmo contexto. Sublinhe-se: enquanto o cooperativismo tradicional se remodelava e readequava ao neoliberalismo no Brasil, buscando utilizá-lo com vistas à expansão de sua lucratividade, o cooperativismo popular apenas surgia na década neoliberal, em razão de uma condição objetiva - qual seja, a necessidade de criação de alternativa de trabalho e renda para trabalhadores desempregados. Assim, por meio de experiências plurais e heterogêneas, surgem entidades com caráter “contestatório” ou, em outro sentido, organizadas por trabalhadores pobres, inconformados com sua situação de força de trabalho sobrante.

Em contraposição ao cooperativismo tradicional, portanto, buscavam configurar sociedades de pessoas, e não de capital; utilizavam o benefício da imunidade tributária do ato cooperativo para buscar a sobrevivência do empreendimento, e não para gerar lucro; valorizavam a gestão cooperativa, ainda que com dificuldades para sua implementação, estas oriundas da necessidade de utilização de princípios empresariais para a sobrevivência de empreendimentos econômicos, ainda que cooperativos em essência. 
O cooperativismo popular caminha ao lado da proposta teórica de economia solidária ${ }^{9}$. O conceito de economia solidária é debatido por diversos autores, não raro em desacordo. Escapa às pretensões deste trabalho realizar uma sistematização bibliográfica vertical a esse respeito. Ainda assim, e com razoável distância entre eles, podem-se citar como principais idealizadores da economia solidária, na América Latina, os professores Razeto, Coraggio e Singer ${ }^{10}$. Uma visão oficial, no âmbito do Estado brasileiro, é a fornecida pelo MTE e pela SENAES ${ }^{11}$. Uma visão realista, em alternativa, é apresentada por Carleial e Paulista ${ }^{12}$.

Observe-se que o âmbito da economia solidária é uma parte do cooperativismo, ao mesmo tempo que é mais amplo do que ele. Apenas uma parte, e não a totalidade do cooperativismo, porque não configuram experiências de economia solidária aquelas ligadas ao cooperativismo tradicional. Mais amplo do que o cooperativismo, por outro lado, porque se inclui nela uma série de outras experiências, alheias à forma jurídica cooperativa em sentido estrito, como associações e grupos informais.

Algumas principais dificuldades enfrentadas pelos empreendimentos se expressam, justamente, na forma jurídica que eles assumem. O direito é, a um só tempo, solução e problema para a maior parte dos empreendimentos, como se verá a seguir.

\section{TRABALHO AUTÔNOMO, DIFICULDADES DO COOPERATIVISMO POPULAR E DEMANDA POR UM NOVO MARCO JURÍDICO}

Na década de 1980, a economia brasileira ingressa em longa fase de baixo dinamismo nas atividades produtivas. O resultado é a maior distância entre o aumento da população economicamente ativa (PEA) e a expansão do emprego (POCHMANN, 2012, p. 25). No quadrante 1980-2000, é significativo o aumento da força de trabalho sobrante, o que possibilita o

\footnotetext{
${ }^{9}$ Para Antônio Cruz, economia solidária é “o conjunto dos empreendimentos econômicos associativos em que (i) o trabalho, (ii) os resultados econômicos, (iii) a propriedade de seus meios (de produção, de consumo, de crédito etc.), (iv) o poder de decisão e (v) os conhecimentos acerca de seu funcionamento são compartilhados solidariamente por todos aqueles que deles participam” (CRUZ, 2006).

${ }^{10}$ Para uma comparação entre as propostas de "economia da solidariedade” (Razeto), “economia popular e do trabalho” (Coraggio) e “economia solidária como novo modo de produção” (Singer), veja-se CRUZ, 2006, p. 37-55.

11 “A economia solidária vem se apresentando, nos últimos anos, como inovadora alternativa de geração de trabalho e renda e uma resposta a favor da inclusão social. Compreende uma diversidade de práticas econômicas e sociais organizadas sob a forma de cooperativas, associações, clubes de troca, empresas autogestionárias, redes de cooperação, entre outras, que realizam atividades de produção de bens, prestação de serviços, finanças solidárias, trocas, comércio justo e consumo solidário. Nesse sentido, compreende-se por economia solidária o conjunto de atividades econômicas de produção, distribuição, consumo, poupança e crédito, organizadas sob a forma de autogestão". Disponível em: $<$ http://portal.mte.gov.br/ecosolidaria/o-que-e-economia-solidaria.htm>. Acesso em: 25 jan. 2015.

12 "A economia solidária, tal como ela se apresenta, retrata formas de resistência política aos efeitos deletérios dessa fase do desenvolvimento capitalista e manifestações frágeis de luta pela sobrevivência material” (CARLEIAL; PAULISTA, 2008, p. 32).
} 
entendimento do quadro no interior do qual se desenvolve a economia solidária e o cooperativismo popular.

Na década de 2000, expandem-se ocupações formais e informais, a maior parte delas para trabalhadores de “salário de base”, isto é, com renda de até 1,5 salário mínimo. Geraram-se 21 milhões de postos de trabalho. Destes, 94,8\% tiveram rendimento de até 1,5 salário mínimo (POCHMANN, 2012, p. 27).

Na década de 1980, foram criados 18,1 milhões de novas ocupações; 25,4\% com remuneração de baixa renda e 33,1\% com remuneração igual a ou acima de cinco salários mínimos. Na década de 1990, por outro lado, foram gerados 11 milhões de novos postos de trabalho; 53,6\% não previam remuneração. Instituía-se novo padrão de trabalho, com redução do assalariamento (cerca de 260 mil postos de emprego a menos) e crescimento das ocupações por conta própria. Em 2000, a faixa daqueles que recebiam até 1,5 salário mínimo passa por redução, apresentando percentual de 34,3\% do total. Trinta anos antes, 64,3\% dos ocupados recebiam essa contrapartida remuneratória. Mas é justamente nessa década que o quadro se modifica. Em 2009, o percentual volta a crescer e atinge quase a metade do total (POCHMANN, 2012, p. 38).

As ocupações de baixa renda, assim, constituem "a base da pirâmide social”. Sua relevância se evidencia pela soma de 47,8\% da força de trabalho ocupada e 24,5\% das remunerações do País (POCHMANN, 2012, p. 29). No universo de trabalhadores de salário de base, 75\% são assalariados. Destes, dois terços possuem carteira assinada. Permanece um universo de $30 \%$ de ocupações geradas sem carteira assinada. Isto é, sem assalariamento - ao menos no formato clássico, com direitos sociais garantidos. No interior dessas vagas, verifica-se a geração de trabalho autônomo, como importante fenômeno da base da pirâmide social brasileira.

Ocupações autônomas, para Pochmann, são aquelas “que, em geral, são desempenhadas por natureza própria, sem subordinação e nem sempre com a presença de algum meio de produção, pois isso seria próprio das atividades de empregadores” (POCHMANN, 2012, p. 69).

O trabalho não assalariado de natureza autônoma, com efeito,

[...] vem respondendo pela parcela crescente do total das ocupações brasileiras. Em 2009, por exemplo, o trabalho autônomo era exercido por 22,9 milhões de ocupados, o que significou praticamente um quarto de todos os postos de trabalho do país. Quatro décadas antes, em 1970, 7,2 milhões de pessoas eram trabalhadoras autônomas, o que representava apenas 6,3\% do total de ocupados (POCHMANN, 2012, p. 78, grifos nossos). 
São números significativos. Referem-se a trabalhadores de baixa remuneração ${ }^{13}$, sem proteção trabalhista, predominantemente homens (embora com tendência contrária em andamento $)^{14}$, com recente maioria não branca ${ }^{15}$ e, de maneira geral, com baixa ação sindical ${ }^{16}$.

O quadro se completa com a informação geográfica, sob dois aspectos. Em 1970, o trabalho autônomo se concentrava no meio rural (i) e na região Nordeste (ii). Quanto ao primeiro aspecto (i), 47\% do trabalho autônomo era rural em 1979, porcentagem que diminui para 29,5\% em 2009. Já o meio urbano concentrava 33\% dos autônomos em 1970, passando a 47\% em 2009. Segundo Pochmann, a crescente modificação do trabalho autônomo (do meio rural para o urbano) se reflete também em modificações entre as grandes regiões do País. Eis o segundo aspecto (ii): em 1970, mais de 47\% dos trabalhadores autônomos viviam na região Nordeste, com apenas 17,6\% na região Sudeste. Passados quarenta anos, as regiões Nordeste e Sudeste respondem por parcela equivalente dos trabalhadores autônomos - qual seja, 34\% cada uma (POCHMANN, 2012, p. 81 et seq.).

A principal constatação de Pochmann, a respeito dos deslocamentos do trabalho autônomo, refere-se a um movimento mais geral. É o de crescente deslocamento do trabalho, do rural para o urbano, independentemente do tipo de trabalho. É o movimento de expropriação primária de trabalhadores (CARLEIAL, 1986, p. 28; FONTES, 2010, p. 44).

Os números são relevantes. Apontam que, aproximadamente, um a cada quatro trabalhadores urbanos é autônomo no Brasil. Sem dúvida, a relevância desse indicador afirma que a expropriação primária brasileira produz possibilidades baixas de assalariamento e acesso a direitos sociais. É o movimento de expropriação secundária de trabalhadores (FONTES, 2010, p. 44).

Assim, a última década assinala crescimento do trabalho assalariado e do autônomo, bem como queda do desemprego no Brasil. São esses os dois principais indicadores materiais que fornecem subsídio para a compreensão do cooperativismo do trabalho, que gera ocupação e renda para trabalhadores autônomos coletivos.

Por que são autônomos e quais as dificuldades deste um quarto da força de trabalho ocupada brasileira? Um primeiro indicador já foi citado e se refere à situação de pobreza: não é

\footnotetext{
13 “A cada grupo de três ocupações autônomas, duas podem ser atribuídas aos trabalhadores de salário de base, pertencentes à base da pirâmide social brasileira” (POCHMANN, 2012, p. 78).

${ }_{14}$ Aumenta a presença feminina nesses postos de trabalho, mas eles ainda são ocupados em maioria por homens. Em 1970, as mulheres representavam 13,1\% do total. Em 2009, representavam 37,3\% do total (POCHMANN, 2012, p. 79).

15 “Cada vez mais o trabalho autônomo vem sendo exercido pela população não branca. Até o fim da década de 1990 , o contingente numérico dos trabalhadores brancos era levemente superior dentro do total das ocupações autônomas. No ano de 2009, porém, os ocupados não brancos representam quase 55\% do total do trabalho autônomo no país” (POCHMANN, 2012, p. 81).

16 “[...] observa-se baixa presença sindical, uma vez que menos de $15 \%$ dos trabalhadores são filiados à entidade de representação de seus interesses laborais” (POCHMANN, 2012, p. 78).
} 
casual que, a cada três ocupações autônomas, duas sejam ocupadas por trabalhadores de baixa remuneração. É neste universo que se localizam os empreendimentos de economia solidária.

Relembre-se que, a cada dez ocupações geradas nos anos 2000, sete foram empregos formais. Restam três ocupações que não se enquadram no emprego formal, mais as que não foram geradas, como explicação da existência de empreendimentos de economia solidária (EES). Face ao desemprego ou à insegurança das diversas informalidades, a vida reclama soluções. Uma delas é o trabalho autônomo, com o cooperativismo popular se apresentando como possibilidade.

O número total de EES diminuiu, entre 2008 e 2013, conforme apresentado na primeira seção. Em que pese o número total de empreendimentos ter caído, a informação sobre os motivos pelo qual constituíram empreendimentos é relevante. Vejam-se os quatro mais citados (SENAES, 2013):

1) 9.624 afirmam que buscavam uma "fonte complementar de renda para os associados";

2) 9.106 informam que constituíram EES como "uma alternativa ao desemprego";

3) 8.471 visualizavam possibilidade de "obtenção de maiores ganhos em um empreendimento associativo";

4) 8.024 tinham como objetivo “desenvolver uma atividade onde todos são donos”.

Dos quatro motivos mais citados, portanto, apenas um é “ideológico”. Os outros três referem-se a condições materiais de existência, seja para a sobrevivência direta (face ao desemprego), seja para o aumento da renda (face à baixa remuneração).

As dificuldades enfrentadas pelos empreendimentos são variadas. Entre elas, destacam-se o financiamento e a forma organizativa. O financiamento é tido como uma necessidade para mais de dois terços dos empreendimentos ${ }^{17}$. A forma organizativa prossegue sendo um obstáculo imposto pelo marco jurídico, visto que a maioria dos empreendimentos são regularizados como associações (11.823) ou grupos informais (6.018). São poucos os que conseguem chegar à forma jurídica cooperativa (1.740) (SENAES, 2013).

Um dos principais obstáculos à constituição de empreendimentos na forma jurídica cooperativa é o número mínimo de sócios. Só podem ser consideradas sociedades cooperativas singulares, nos termos da Lei n. 5.764/1971, aquelas que possuírem pelo menos 20 (vinte) associados (art. 6 , I). Como destacam Kruppa, Gonçalves e MacDonald, a nova Lei de Cooperativas de Trabalho (Lei n. 12.690/2012) apresenta flexibilização desse requisito, que passa a

\footnotetext{
17 13.764 EES afirmaram precisar de financiamento no momento. 5.944 afirmaram não precisar de financiamento no momento.
} 
ser de 7 (sete) sócios. Em 2012, segundo os autores, esse dispositivo poderia beneficiar “4.926 empreendimentos econômicos solidários que têm entre 7 e 19 associados” (KRUPPA; GONÇALVES; MACDONALD, 2012, p. 24).

Como exposto, a legislação cooperativista não teve como objetivo original fomentar iniciativas de cunho popular. Pelo contrário, representava os interesses da modernização conservadora do campo no Brasil, apoiada pela ditadura civil-militar. A expressão mais desenvolvida desse processo foi a constituição e a consolidação da OCB, que há décadas representa e defende os interesses do cooperativismo tradicional.

Inúmeras características da Lei 5.764/1971 exemplificam dificuldades impostas ao cooperativismo popular. Especial destaque deve ser dado aos entraves jurídicos e burocráticos para a constituição e manutenção das cooperativas. Um indício sobre o motivo da redução de cooperativas pode ser encontrado nos dados disponibilizados no SIES. Segundo dado já citado, em 2012 mais de 60\% dos empreendimentos se organizavam como associação e quase um terço deles eram grupos informais. Apesar de apenas 9,7\% dos empreendimentos se apresentarem como cooperativas, estas reuniam quase 40\% do total de associados em EES (37,53\%) (SIES, 2013).

O problema é antigo e já se apresentava em 2007. Verificava-se, naquele ano, que os empreendimentos eram, em maior parte, associações. Em aparente contraste, a maior parte das pessoas envolvidas com a economia solidária se organizava em cooperativas. Na verdade, tem-se uma unidade dialética: o grau de formalização é relacionado com a capacidade de os empreendimentos agregarem mais ou menos pessoas. Havia uma dificuldade para a constituição de cooperativas, haja vista maior entrave formal. As cooperativas já existentes, no entanto, possuíam maior número de associados e, pode-se afirmar, maior probabilidade de desenvolvimento e manutenção (KRUPPA; GONÇALVES; MACDONALD, 2012, p. 21 et seq.).

Os dados econômicos dos empreendimentos confirmam essa tese. As cooperativas representavam, em 2007, apenas 10\% dos empreendimentos de economia solidária. Em contraste a essa baixa porcentagem, apresentavam VPM-T (Valor de Produção Mensal Total) de mais da metade de todo o VPM-T contabilizado entre os empreendimentos, somando a significativa porcentagem de $60 \%$ do total. Os grupos informais, que representavam $37 \%$ dos empreendimentos cadastrados, geravam apenas 5\% do VPM-T. As associações, 52\% do total dos empreendimentos, contabilizavam apenas 29\% do VPM-T (KRUPPA; GONÇALVES; MACDONALD, 2012, p. 24). 
A informalidade é feminina, rural, nordestina ${ }^{18}$. A viabilidade econômica dos empreendimentos é um desafio, com pouco mais da metade deles conseguindo cobrir suas despesas ou possuindo algum tipo de sobra ${ }^{19}$. Não se trata de uma casualidade, mas de operações práticas impossibilitadas pela informalidade, como a emissão de notas fiscais e a restrição à circulação dos produtos $^{20}$.

Percebe-se que há relação direta entre nível de formalidade do empreendimento e sua comercialização em âmbito comunitário, municipal ou estadual. Aos grupos informais, por exemplo, resta majoritariamente a alternativa comunitária (72,31\%). Como sistematizam Kruppa, Gonçalves e MacDonald (2012, p. 27-28):

Desta maneira, grande parte dos grupos informais limita-se a vender na própria comunidade (72,31\%) ou no município de que fazem parte $(19,84 \%)$. Regionalmente ou em nível estadual, a venda é mínima. São também os que mais afirmam ter dificuldade de comercialização. Conforme se caminha para as cooperativas, o número de empreendimentos que vendem em sua região $(15,77 \%)$ ou no estado $(13,28 \%)$ vai aumentando significativamente. Porcentagem insignificante de empreendimentos disputa 0 mercado das compras públicas. Apenas 2\% fornecem a órgão governamental.

Conclui-se, assim, que a maior parte dos cooperados realiza sua atividade com objetivos materiais, ou seja, de sobrevivência, complementação de renda, alternativa ao desemprego. É minoritário o grupo de pessoas que busca, no cooperativismo, desenvolver atividade em que ausente a hierarquia entre patrões e empregados.

Assim, se o objetivo principal do cooperativismo tem sido o da sobrevivência material, deve-se analisar o nível de vida que ele oportuniza aos cooperados. Os dados não são positivos.

Em 2008, 50\% dos empreendimentos viabilizavam aos seus sócios remuneração com valor até meio salário mínimo; e, em 26,1\%, a remuneração era de meio a um salário mínimo (SENAES, 2008). Em 2013, as dificuldades materiais prosseguem latentes. O mapeamento do SIES indica que cerca de 2/3 dos empreendimentos possuem como duas principais dificuldades sua viabilização econômica (13.108 EES) e a geração adequada de renda aos sócios (14.503). A terceira maior dificuldade concerne à própria existência do empreendimento: 11.048 EES apontaram como desafio a manutenção da união do grupo (SENAES, 2013).

\footnotetext{
18 "Podemos assim afirmar que, além de um fenômeno eminentemente rural, as associações são, em sua maioria, nordestinas. Outra característica é que a informalidade significa, além de um recorte urbano, também um recorte de gênero. De fato, conforme podemos observar na Tabela 4, os grupos informais são mais frequentemente formados por mulheres, as associações já um pouco menos e as cooperativas são majoritariamente formada por homens” (KRUPPA; GONÇALVES; MACDONALD, 2012, p. 23).

19 "Em relação ao desafio da viabilidade econômica, observa-se que 38,1\% dos EES conseguiram obter sobras em suas atividades, enquanto somente $14,9 \%$ foram deficitários no último ano. Ao mesmo tempo, 33,8\%, embora não obtendo sobras, conseguiram pagar as despesas realizadas (KRUPPA; GONÇALVES; MACDONALD, 2012, p. 25).

${ }^{20}$ Veja-se tabela sobre relação entre formalização e comercialização em KRUPPA; GONÇALVES; MACDONALD, 2012, p. 27.
} 
Os dados apontam, inequivocamente, para o seguinte panorama: a maior causa de existência dos EES são as condições materiais de existência de seus sócios. Buscam-se constituir alternativas de trabalho e renda e, por isso, gestam-se os empreendimentos. A alternativa, no entanto, mantém a precariedade das condições de vida dos sócios. Tem-se, pois, uma solução que mantém o problema, ainda que modificado.

A modificação reside no seguinte: a alternativa que se constrói possui dificuldades para garantir renda adequada aos sócios (14.503), quando não para se viabilizar economicamente (13.108) ou para se manter existente, unida, coletiva (11.048). Da dificuldade material individual, passa-se à necessidade de financiamento, coletiva. Dos 19,7 mil empreendimentos, 13.764 informam necessitar de financiamento; apenas 5.944 indicam ausência dessa necessidade (SENAES, 2013).

Veja-se que os diversos dados indicam, de forma bastante contundente, as dificuldades materiais dos empreendimentos. Trata-se de um deslocamento: das dificuldades de pessoas (individualmente), passa-se às dificuldades de cooperados (como parte do empreendimento).

As descontinuidades devem ser ressaltadas, eis que o problema passa a ser coletivo, e não mais individual. Eis um deslocamento ideológico. Mantêm-se latentes, no entanto, permanências. Prossegue existente a condição de pobreza ou dificuldade financeira das pessoas cooperadas. A permanência, nesse sentido, diz respeito às condições materiais de existência, na vida e no trabalho.

\section{O NOVO MARCO JURÍDICO DO COOPERATIVISMO: PL N. 03/2007 E LEI N. $12.690 / 2012$}

Nesse cenário, marcado por pobreza e informalidade, o novo marco jurídico se apresenta como uma necessidade. É defendido como um dos principais desafios para o desenvolvimento e democratização do cooperativismo no Brasil.

Há dezesseis anos é debatido um novo marco jurídico para o cooperativismo no Brasil. Alguns projetos com essa intenção já foram referidos e problematizados na presente pesquisa, como o PL n. 171/1999, de autoria de Osmar Dias, então filiado ao PSDB/PR, arquivado em 2007. No mesmo ano de 1999, outros dois projetos foram apresentados: o PL n. 428, de José Fogaça (PMDBRS) e o PL n. 605, de Eduardo Suplicy (PT-SP). Os três projetos foram arquivados pelo mesmo motivo - qual seja, decurso do prazo de oito anos de tramitação ${ }^{21}$.

\footnotetext{
${ }^{21}$ Regimento Interno do Senado, art. 332, § $1^{\circ}$.
} 
Em 2007, mesmo ano do arquivamento, os Senadores Osmar Dias e Eduardo Suplicy propuseram novos projetos de lei para o tema (PLS n. 03 e 153/2007), com redação muito semelhante à dos projetos anteriores. Recentemente, a Senadora Gleisi Hoffmann (PT/PR) foi designada relatora dos projetos e apresentou um substitutivo a eles, aprovado no Senado em $16 / 12 / 2014$.

Somando-se à Lei n. 12.690/2012, que trata das cooperativas de trabalho, o substitutivo pode vir a representar o que há de mais relevante na legislação cooperativista. A atualização do marco jurídico, entretanto, não significa necessariamente uma modificação dos rumos do cooperativismo no Brasil. Ainda assim, os interesses que a motivam não são pequenos, e seus dezesseis anos de debate seguramente informam contradições latentes da forma jurídica cooperativa.

Os principais campos envolvidos no debate sobre a renovação da forma jurídica cooperativa, a partir da defesa do cooperativismo popular, foram a UNICAFES (União Nacional das Cooperativas da Agricultura Familiar e Economia Solidária), a UNISOL (União e Solidariedade das Cooperativas e Empreendimentos de Economia Social do Brasil), a CONCRAB (Confederação das Cooperativas de Reforma Agrária), a ANTEAG (Associação Nacional dos Trabalhadores de Empresas Autogeridas e Cogeridas) e o FBES (Fórum Brasileiro de Economia Solidária). Embora com diferenças entre si, possuem no antagonismo à OCB seu principal eixo de unificação. Três delas, em janeiro de 2014, resolveram formar a UNICOPAS (União Nacional das Organizações Cooperativistas Solidárias) $)^{22}$.

O surgimento da UNICOPAS é relacionado ao debate acerca do novo marco jurídico. A Lei n. 5.764/1971 estabelece representação exclusiva pela OCB. Entre as consequências dessa prescrição, destaca-se o acesso exclusivo aos fundos públicos, como o SESCOOP. O PL n. 03/2007, em sua redação original, mantinha a necessidade de registro de toda cooperativa na OCB.

Além do debate sobre a representação, outros dois pontos controversos são reticências do projeto de 1999, de contexto neoliberal: primeiro, sobre a amplitude do ato cooperativo, com consequências sobre o regime tributário; e segundo, sobre abertura do capital das cooperativas, com possibilidade de participação de pessoas jurídicas com fins lucrativos como suas sócias.

Vejam-se, em detalhe, os três pontos controversos.

(a) Sobre a representação: o substitutivo de Gleisi Hoffmann propõe um consenso entre os atores envolvidos. Mantém a necessidade de filiação a uma entidade nacional. Oportuniza, no

\footnotetext{
${ }^{22}$ A união deu-se entre UNICAFES, CONCRAB e UNISOL.
} 
entanto, duas possibilidades: a tradicional OCB e a popular UNICOPAS, recentemente criada (art. $8^{\circ}$, II; e art. $78, \S \S 1^{\circ}$ e $2^{\circ}$ ).

(b) Sobre a abertura do capital: o texto original de Osmar Dias previa a possibilidade de instituição de capital rotativo (art. 15) e emissão de certificados de aporte de capital (art. 54-57). O substitutivo de Gleisi Hoffmann não prevê essas possibilidades, mantendo concepção mais próxima ao cooperativismo clássico.

(c) Sobre o regime tributário: o texto de Osmar Dias buscava a ampliação do conceito de ato cooperativo, equiparando ao seu conceito “os negócios auxiliares ou meios, indispensáveis à consecução dos objetivos sociais” (art. 48, § $2^{\circ}$ ). A intenção era de extensão do tratamento adequado ao ato cooperativo, previsto na Constituição Federal (CF, art. 146, III, “c”). O texto de Gleisi Hoffmann mantém o conceito anterior de ato cooperativo, mais restritivo (art. 46 e 49).

Outrossim, evidenciem-se duas outras novidades do substitutivo. A primeira, referente ao número mínimo de associados. Já no PL n. 171/1999, Osmar Dias propunha que o número mínimo de associados fosse reduzido para sete sócios (art. $4^{\circ}$, I). O autor manteve a mesma previsão na redação original do PLS n. 03/2007. Gleisi Hoffmann, no seu substitutivo, modifica esse entendimento. Realiza previsão genérica, em que o mínimo necessário para a constituição de cooperativa singular é a soma do número mínimo dos órgãos de administração e fiscalização (art. $\left.4^{\circ}, \mathrm{I}\right)$. Com efeito, pode-se interpretar esse mínimo como sendo seis pessoas (três de cada um dos órgãos, conforme disposto nos art. 33 e 41).

A segunda novidade que merece destaque é a previsão de cooperativas de ajuda mútua ou viés solidário. Esse tipo de cooperativa não encontra correspondente histórico em nenhum marco legal brasileiro. Seu objetivo, segundo o substitutivo, é a atuação “em segmentos sociais economicamente frágeis ou vinculadas a iniciativas de superação da pobreza” (art. $2^{\circ}$, § $2^{\circ}$ ). Para tanto, "poderão receber prioridade ou facilidades no acesso a recursos públicos e, também, tratamento tributário e fiscal diferenciado” (art. $\left.2^{\circ}, \S 3^{\circ}\right)$.

Sem dúvida, o substitutivo busca facilitar a instituição de cooperativas e diminuir a informalidade. Evita o enfrentamento do regime tributário, um dos poucos consensos entre cooperativismo tradicional e cooperativismo popular ${ }^{23}$. Mais do que isso, no entanto, refuta as propostas de cunho neoliberal, que se reapresentavam desde o PL n. 171/1999, e institui a

\footnotetext{
${ }^{23}$ Sobre o embate entre cooperativismo (tradicional e popular) e Secretaria da Receita Federal, afirmam Kruppa, Gonçalves e MacDonald (2012, p. 53): “As primeiras, pedindo uma legislação tributária e uma definição de ato cooperativo mais amplo e que traga maiores benefícios ao conjunto das cooperativas e o segundo (o governo) preocupado em não transformar a tributação de cooperativas em um grande instrumento de evasão fiscal para setores consolidados”.
} 
possibilidade de representação nacional por parte do cooperativismo popular, com o reconhecimento da UNICOPAS.

As cooperativas de trabalho, por outro lado, representam importante e controvertida espécie da forma jurídica cooperativa. Não eram previstas na Lei n. 5.764/1971. Seguem sem previsão no substitutivo de Gleisi Hoffmann, apresentado acima. A previsão é dada por lei específica, que complementa a regulamentação geral do cooperativismo.

Por meio da Lei n. 12.690/2012, foi consagrada a figura da cooperativa de trabalho. No dispositivo legal, foram garantidos direitos mínimos ao trabalhador cooperado. A iniciativa apresenta dificuldades, ao mesmo tempo, às “cooperfraudes” e à viabilização das cooperativas populares. Veja-se em detalhe.

O cooperativismo tem como marcos gerais a Lei n. 1.637, de 1907, o Decreto n. 22.239, de 1932 e, em especial, a Lei n. 5.764, de 1971, para além dos dispositivos presentes na Constituição Federal de 1988 (art. 5, XVIII; art. 146, III, “c”; art. 174, § 2º). As cooperativas de trabalho têm como principal marco legal, prévio à Lei n. 12.690/2012, a Lei n. 8.949/1994²4. Relembre-se que a legislação de 1994 teve como proponente o $\mathrm{MST}^{25}$.

A Lei n. 12.690/2012 estabelece uma série de princípios, a maioria deles já previstos na Lei Geral do Cooperativismo ${ }^{26}$. Diferem-se, no seu art. $4^{\text {o }}$, os tipos de cooperativas de trabalho quais sejam, de produção e de serviços. Estabelece o número mínimo de sete associados para sua constituição (art. $6^{\circ}$ ). Elenca, outrossim, garantia de direitos aos sócios, em rol não exaustivo:

Art. $7^{\circ}$ A Cooperativa de Trabalho deve garantir aos sócios os seguintes direitos, além de outros que a Assembleia Geral venha a instituir:

I - retiradas não inferiores ao piso da categoria profissional e, na ausência deste, não inferiores ao salário mínimo, calculadas de forma proporcional às horas trabalhadas ou às atividades desenvolvidas;

\footnotetext{
${ }^{24}$ A Lei n. 8.949/1994 acrescenta o parágrafo único no art. 442 da CLT, com a seguinte redação: “Qualquer que seja o ramo de atividade da sociedade cooperativa, não existe vínculo empregatício entre ela e seus associados, nem entre estes e os tomadores de serviços daquela”.

25 “No princípio dos anos 1990, ex-sócios de cooperativas vinculadas ao Movimento dos Trabalhadores Sem Terra (MST) passaram a denunciá-las à Justiça do Trabalho, requerendo retroatividade de direitos trabalhistas. Em função disso, o MST solicitou ao Partido dos Trabalhadores (PT) que propusesse uma emenda ao Artigo 442 da CLT determinando a inexistência de vínculo empregatício entre a cooperativa e seus sócios, e entre estes e os tomadores de serviços daquela. A aprovação da emenda em 1994, em tempo recorde, diga-se de passagem, embora buscasse garantir segurança jurídica e econômica às cooperativas de trabalhadores, desencadeou a proliferação de falsas cooperativas de trabalho em setores típicos da terceirização, como limpeza, segurança, manutenção, auxílio a escritórios, recepção etc.” (PEREIRA; SILVA, 2012, p. 69).

${ }^{26}$ Destacam-se, entre os princípios específicos das cooperativas de trabalho, os seguintes: Lei n. 12.690, art. 3: "VIII preservação dos direitos sociais, do valor social do trabalho e da livre iniciativa; IX - não precarização do trabalho; X respeito às decisões de assembleia, observado o disposto nesta Lei; XI - participação na gestão em todos os níveis de decisão de acordo com o previsto em lei e no Estatuto Social”. Disponível em: <http://goo.gl/ZKn7W4>. Acesso em: 4 fev. 2015.
} 


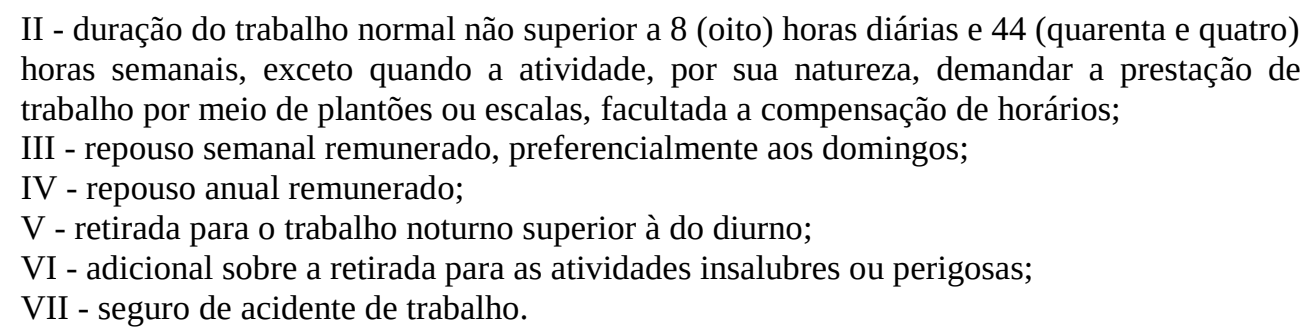

Do ponto de vista histórico, é apenas nos anos 1980 que as cooperativas de trabalho começam a organizar-se e ganhar visibilidade; e, a partir da década de 1990, expandem-se no contexto da reestruturação produtiva (SILVA, 2006, p. 150).

Em 2003, cerca de 27\% das 7.355 cooperativas cadastradas na OCB eram cooperativas de trabalho, configurando-se como maior ramo de cooperativas no Brasil. Em 2010, este deixa de ser o maior ramo, visto que o número de cooperativas era de 1.024; em 2011, eram 966 empreendimentos, com 188.644 cooperados (OCB, 2011).

Embora com queda no número de empreendimentos, mantiveram-se tentativas de regulamentar tais cooperativas de trabalho, mesmo antes da Lei n. 12.690/2012. Citem-se o Projeto de Lei n. 4.622, de 2004, cuja justificativa era garantir maior desenvolvimento a uma "realidade consolidada”, mediante regulamentação da situação de precariedade existente (SILVA, 2006, p. 151).

O acesso a direitos restringe as condições de "competitividade" das cooperativas de trabalho e, portanto, diminui a possibilidade de preços de contratação inferiores aos de empresas de prestação de serviços. Ao mesmo tempo, as cooperativas menores, em especial as constituídas por trabalhadores em situação de pobreza, passam a ter novas dificuldades na sua operação - isso porque os trabalhadores tornam-se a um só tempo portadores de direitos trabalhistas e devedores dos direitos em relação a si mesmos.

Assim sendo, a Lei, aparentemente carregada de vontades "verdadeiras" e "sinceras" de garantir direitos, a um só tempo estimula um novo tipo de institucionalidade do trabalho, não regulamentada pela CLT, e traz maiores dificuldades ao cooperativismo popular. O empreendedorismo, estimulado por este cooperativismo, torna-se mais difícil e custoso.

A SENAES, desde seu início, busca combater as cooperfraudes. Com propostas alternativas, o FBES também buscou a extensão de direitos a trabalhadores cooperados. Foi da Secretaria, no entanto, a proposta aprovada de regulamentação das cooperativas de trabalho. A posição oficial da SENAES é de que o objetivo seria realizar a extensão de direitos sociais aos trabalhadores cooperados (GONÇALVES, 2014, p. 195). 
Assim, ao regulamentar a situação no que se refere às cooperativas tradicionais, a intenção anunciada é de diminuição dos efeitos da precarização do trabalho, com garantia mínima de direitos. No entanto, deve ser questionado se o objetivo não deveria ser o combate à precarização, e não meramente a seus efeitos. É como apontava Silva (2007, p. 151) já sobre a proposta de lei de 2004. Eloísa Gonçalves (2014, p. 197), por outro lado, questiona a existência de sanções à cooperativa (art. 17 e 18) e a ausência de responsabilidade daqueles que se beneficiem de eventual gestão fraudulenta.

Ao debater sobre "autonomia" e "controle” nas relações entre os empreendimentos solidários e as empresas contratantes de seu serviço, Selma Silva (2007, p. 166) afirma que se trata de uma espécie de "autonomia controlada", na medida em que a autonomia é evocada pelas empresas apenas quando o tema em questão são os custos e a responsabilidade sobre o trabalho. Em paralelo, no cotidiano das relações de trabalho, a relação entre empresas contratantes e cooperativas são, em verdade, de submissão destas em relação àquelas. Conclui que um elemento comum, entre a cooperativa tradicional e a popular, acaba sendo o da dominação do trabalho.

O direito do trabalho prescreve: quem dirige a atividade econômica deve suportar seus riscos. O trabalho autônomo pressupõe que os trabalhadores dirigem a atividade econômica; por isso, restam como responsáveis pela garantia de seus direitos sociais. No entanto, a maior parte dos trabalhadores autônomos possui baixa renda (dois terços). Já os trabalhadores cooperados, tidos como autônomos coletivos, elencam como três principais dificuldades (a) a renda dos sócios, (b) a viabilidade econômica dos empreendimentos e (c) a manutenção da união coletiva do grupo. O cenário, sem dúvida, não é de quem “dirige” atividade econômica.

Sob essa máscara ou fundamentação (“dirigir a atividade econômica”), mantém-se sua decorrência jurídica (“suportar os riscos”). A proteção ao trabalho, dessa forma, resta desconstituída e, ainda pior, tornada responsabilidade daqueles que não possuíam alternativas.

A renovação da forma jurídica cooperativa busca “consolidar” e “expandir direitos” ao trabalho autônomo coletivo. Entretanto, não o faz em resposta ao desemprego. A única base material que lhe motiva é a consolidação de uma nova institucionalidade do trabalho.

A autonomia proposta, pois, dá-se em alternativa ao emprego, e não ao desemprego. Consolida-se como um movimento ou tendência de expropriação de direitos e, portanto, como uma forma de precarização do trabalho brasileiro. Três cenários, concernentes ao trabalho regulado pelo cooperativismo, devem ser destacados: (a) cooperativismo tradicional e assalariamento, (b) “cooperfraudes” ou “coopergatos” e (c) cooperativismo popular. As distâncias são relevantes e merecem matização. 
O cooperativismo tradicional não corresponde ao ideário do cooperativismo clássico. Beneficia-se costumeiramente de assalariamento, inclusive para aumentar as receitas oriundas do SESCOOP. Não é, portanto, um modelo de trabalho “autônomo” que dirige atividades econômicas. O primeiro cenário é de setores tradicionais, que reproduzem a lógica do assalariamento.

As “cooperfraudes” ou “coopergatos”, por outro lado, flexibilizam diretamente os direitos sociais. Oportunizam a diminuição do preço da força de trabalho, com a subtração de direitos sociais de trabalhadores. O segundo cenário, pois, é de flexibilização direta dos direitos sociais.

O cooperativismo popular, por fim, possui intenção de se constituir como trabalho autônomo coletivo. Realiza deslocamentos ideológicos, ainda que com contradições. Possibilita a apreensão de que o problema das condições materiais de existência não é individual, mas coletivo. Busca forjar, portanto, uma autonomia coletiva dos cooperados, em contraposição a respostas individuais para a situação de pobreza. Ao manter a pobreza ou as dificuldades de renda, no entanto, dá forma a um tipo peculiar de autonomia: uma autonomia precária, dependente do Estado, cujo foco da existência não é a luta política, mas a luta econômica pela sobrevivência do empreendimento ${ }^{27}$.

As premissas para essa conclusão são variadas e conectadas ao trabalhador cooperado, individualmente, e ao empreendimento, de forma coletiva. Quanto ao empreendimento, destaca-se a dependência de financiamento pelo Estado; quanto ao trabalhador cooperado, destacam-se a baixa renda, a ausência de direitos sociais e a insegurança constante no trabalho, oportunizada pela possibilidade de que o EES não logre sucesso econômico.

Em termos jurídicos, a tendência ao crescimento de uma "autonomia precária” figura como desrespeito ao princípio da dignidade da pessoa humana, bem como à proteção do trabalho. Pode-se afirmar, com efeito, que a ausência de “direção de atividade econômica” apresenta uma contradição de difícil resolução no plano do direito. Mantida a situação de pobreza e a ausência de direção de atividades econômicas, é contraditório que os próprios trabalhadores cooperados sejam responsabilizados pelo desrespeito aos seus direitos, como prescreve a Lei n. 12.690/2012.

A autonomia precária, nesse ponto, é resultante do deslocamento ideológico que o cooperativismo popular engendra. A responsabilidade quanto à situação de pobreza é coletiva, e não mais individual. Por um lado, o deslocamento ideológico sugere a alternativa do trabalho coletivo, contra a situação de pobreza individual. Eis a busca pela autonomia. Por outro lado, a precariedade reside, justamente, na distância entre a diretriz (busca por autonomia) e o real concreto dos

\footnotetext{
${ }^{27}$ Ressalva-se a existência de um “movimento cooperativista”, já assinalado, existente em nível nacional, de que o FBES e a UNICOPAS são a maior expressão.
} 
empreendimentos - de maneira geral, com dificuldades financeiras para sua viabilização e para a garantia de direitos.

Reconhecida a autonomia precária dos EES, é contraditória a afirmação de que a renovação da forma jurídica cooperativa representa maior garantia de direitos a trabalhadores cooperados. Pelo contrário: deve-se afirmar que o aumento da responsabilidade trabalhista das cooperativas denota mais uma expressão de seus dilemas. O trabalhador precário coletivo (em forma de cooperativa) não deve ser responsável pelo trabalhador sem direitos sociais que venha a desistir do trabalho autônomo coletivo.

\section{CONSIDERAÇÕES FINAIS}

No Brasil, a forma jurídica cooperativa passa a ter maior consistência a partir da legislação de 1971. Sua consolidação tem como objetivo a utilidade às elites agrárias, no interior dos interesses da modernização conservadora do campo. Nos seus mais de quarenta anos, no entanto, foram possibilitadas condições para que diferentes atores políticos a disputassem.

Os setores populares buscaram realizar a retomada do ideário e das propostas do cooperativismo clássico. Essas propostas não se desenvolveram, no Brasil, por “vontade autônoma” de setores “esclarecidos”. São fruto de um momento histórico determinado, especialmente na década de 1990, quando a base material das relações de trabalho demandou alternativas de trabalho e renda para trabalhadores pobres.

A sociedade cooperativa, concretamente, é de difícil constituição e manutenção. Historicamente controlada por setor agroexportador conservador, seu regramento é avesso às pequenas cooperativas, que dificilmente conseguem se registrar como tais. No mais das vezes, as experiências de economia solidária e cooperativismo popular foram constituídas como grupos informais ou associações.

Ainda assim, era o direito que se achava na rua, nas organizações populares, em formas de organizar a vida e o trabalho. Um direito a trabalhar em cooperação e autonomamente, que não se constituía formalmente, por meio de produção legislativa. Independentemente da possibilidade de adotar formalmente a denominação “cooperativa”, entendia-se como parte do cooperativismo popular e buscava constituir experiências comuns. Diferentes atores foram fortemente influenciados por esse ideário. Com base nele, foram criados milhares de empreendimentos, fóruns, centrais e, até mesmo, uma Secretaria Nacional no âmbito do Ministério do Trabalho e Emprego. 
O ponto delicado reside nas limitações estruturais e ideológicas da forma jurídica cooperativa. A SENAES e os setores populares do cooperativismo, como FBES ou UNICOPAS, apostaram grande parte de seus esforços, em nível nacional, no novo marco jurídico do cooperativismo. Em resposta às coopergatos ou cooperfraudes, incentivaram a criação da Lei n. 12.690/2012. Em resposta à hegemonia do cooperativismo tradicional no acesso aos fundos públicos, bem como às dificuldades de formalização dos empreendimentos, apoiaram o substitutivo de Gleisi Hoffmann ao PL n. 03/2007. Sem dúvida, ambos os projetos representam avanços formais em direitos e atendimento das demandas do cooperativismo popular. A aposta na renovação do marco jurídico, no entanto, trilha caminho paradoxal aos aprendizados da década de 1990.

A análise realizada confere densidade à percepção de que a renovação do marco jurídico é síntese de permanências, e não de rupturas, no campo do cooperativismo - em especial do cooperativismo popular -, como parte do processo de precarização do trabalho no Brasil. Entretanto, essas permanências são permeadas de descontinuidades e paradoxos, sobretudo pelo esforço de autonomia presente nos empreendimentos, o que lhes garante significativa relevância para a formação política e concretização da dignidade dos envolvidos com o cooperativismo popular.

\section{REFERÊNCIAS}

ANTUNES, Ricardo. Adeus ao Trabalho? Ensaio sobre as metamorfoses e a centralidade do mundo do trabalho. 14 ed. São Paulo: Cortez, 2010.

ARAUJO, Luciana Souza de. Cooperativismo e Filosofia Latino-americana: Autogestão como Possibilidade de Libertação? Tese (Doutorado em Direito) - Programa de Pós-Graduação em Direito da Universidade Federal do Paraná, Curitiba, 2014.

BRAGA, Ruy. A Política do Precariado: do populismo à hegemonia lulista. São Paulo: Boitempo, 2012.

BRASIL. Lei Federal n. 5.764, de 16 de dezembro de 1971. Define a Política Nacional de Cooperativismo, institui o regime jurídico das sociedades cooperativas, e dá outras providências. Diário Oficial da União, Brasília, DF, 16 de dezembro de 1971.

. Lei Federal n. 12.690, de 19 de julho de 2012. Dispõe sobre a organização e o funcionamento das Cooperativas de Trabalho; institui o Programa Nacional de Fomento às Cooperativas de Trabalho - PRONACOOP; e revoga o parágrafo único do art. 442 da Consolidação das Leis do Trabalho - CLT, aprovada pelo Decreto-Lei no 5.452, de $1^{\circ}$ de maio de 1943. Diário Oficial da União, Brasília, DF, 19 de julho de 2012. 
Ministério do Trabalho e Emprego. Secretaria Nacional de Economia Solidária. Atlas da economia solidária no Brasil. Brasília: MTE, SENAES, 2008.

. Ministério do Trabalho e Emprego. Secretaria Nacional de Economia Solidária. Atlas da economia solidária no Brasil. Brasília: MTE, SENAES, 2013.

Projeto de Lei n. 03, de 2007 (do Senado Federal). Dispõe sobre as sociedades cooperativas. Diário do Senado Federal, Brasília, 25 de fevereiro de 2015.

Projeto de Lei n. 03, de 2007 (do Senado Federal). Dispõe sobre as regras gerais do Sistema Cooperativista Nacional, que compreende as cooperativas e seus órgãos de representação. Diário do Senado Federal, Brasília, 22 de janeiro de 2007.

. Projeto de Lei n. 171, de 1999 (do Senado Federal). Dispõe sobre as sociedades cooperativas. Diário do Senado Federal, Brasília, 22 de janeiro de 2007.

. Projeto de Lei n. 428, de 1999 (do Senado Federal). Dispõe sobre as sociedades cooperativas. Diário do Senado Federal, Brasília, 22 de janeiro de 2007.

CARLEIAL, Liana Maria da Frota. Acumulação capitalista, emprego e crise: um estudo de caso. São Paulo: IPE/USP, 1986.

CARLEIAL, Liana; PAULISTA, Adriane. Economia solidária: utopia transformadora ou política pública de controle social? In: GEDIEL, José Antônio Peres (Org.). Estudos de direito cooperativo e cidadania. Curitiba: Programa de Pós-Graduação em Direito da UFPR, n. 2, 2008.

COUTINHO, Carlos Nelson. De Rousseau a Gramsci. São Paulo: Boitempo, 2011.

CRUZ, Antônio. A diferença da igualdade: a dinâmica da economia solidária em quatro cidades do Mercosul. Tese (Doutorado em Economia). Instituto de Economia da Universidade Estadual de Campinas (UNICAMP), Campinas, 2006.

FONTES, Virgínia. O Brasil e o capital-imperialismo - teoria e história. 1. ed. Rio de Janeiro: editora da UFRJ, 2010

GONÇALVES, Eloísa Dias. A Reestruturação Produtiva e a Regulamentação das Cooperativas de Trabalho: análise crítica a partir da perspectiva dos catadores de materiais recicláveis. In: RAMOS FILHO, Wilson; COUTINHO, Aldacy Rachid; BORDINHÃO NETO, Rubens. Classes Sociais $e$ (Des)Regulação do Trabalho no Brasil Atual. Bauru, Canal 6, 2014.

KRUPPA, Sonia Maria Portella; GONÇALVES, Alicia Ferreira; MACDONALD, José Brendan (et alli). Regime jurídico das Cooperativas Populares e Empreendimentos em Economia Solidária. Série Pensando o Direito, vol. 46. Brasília: Ministério da Justiça, 2012.

LUDWIG, Celso. Para uma Filosofia Jurídica da Libertação: Paradigmas da Filosofia, Filosofia da Libertação e Direito Alternativo. Florianópolis: Conceito Editorial, 2006.

MÉSZÁROS, István. Estrutura social e formas de consciência. São Paulo: Boitempo, 2011. 
OPUSZKA, Paulo Ricardo. Cooperativismo popular: análise jurídica e econômica. Curitiba: Juruá, 2012.

OLIVEIRA, Francisco de. Crítica à razão dualista: o ornitorrinco. 1 ed. São Paulo: Boitempo, 2013.

PEREIRA, Clara Marinho; SILVA, Sandro Pereira. A nova lei de cooperativas de trabalho no Brasil: novidades, controvérsias e interrogações. In: Mercado de trabalho: conjuntura e análise. n. 53. Brasília: Ipea: MTE, 1996.

POCHMANN, Márcio. Nova classe média? O trabalho na base da pirâmide social brasileira. São Paulo: Boitempo, 2012.

SENAES. Avanços e desafios para as políticas públicas de economia solidária no governo federal 2003/2010. Brasília: SENAES/MTE, 2012.

2014.

. O que é economia solidária? Disponível em: <http://goo.gl/GUeeIh>. Acesso em: 20 ago.

SILVA, Eduardo Faria. A Organização das Cooperativas Brasileiras e a negação do direito fundamental à livre associação. Dissertação (Mestrado em Direito) - Programa de Pós-Graduação em Direito da Universidade Federal do Paraná, Curitiba, 2006.

. Economia solidária e o direito: da utopia à colonialidade. Tese (Doutorado em Direito) Programa de Pós-Graduação em Direito da Universidade Federal do Paraná, Curitiba, 2011.

SINGER, Paul. Cooperativas de trabalho. 2004. Disponível em: <http://goo.gl/LL2Onx>. Acesso em: 15 mar. 2014.

\title{
PARADOXES OF PRECARIOUS AUTONOMY: COOPERATIVIST LEGISLATION AND LABOUR
}

\begin{abstract}
The object of this article is an analysis of the way in which a "precarious autonomy" is constituted in the scope of autonomous work in Brazil, and its permanence with the legislative renewal of cooperative labour. The article is thus divided into three moments. First, the origins of Law n. 5.764/1971 as well as the difference between traditional and popular cooperativism are presented. Secondly, it contextualizes the widening of the low-income autonomous work in relation to the demands of popular cooperativism. Thirdly and lastly, the new cooperativist legal framework in Brazil is analyzed through Bill n. 03/2007, proposed in the Senate, and through Law n. 12.690/2012. The article includes a bibliographical review that enables the analysis of the discontinuities and constancies that occur with the legislative renewal of cooperative labour in Brazil.
\end{abstract}

\section{KEYWORDS}

Autonomous work. Cooperative legislation. Precarious autonomy. 
PARADOXOS DA AUTONOMIA PRECÁRIA: LEGISLAÇÃO COOPERATIVISTA E TRABALHO

Recebido: 26 de janeiro de 2016

Aprovado: 29 de fevereiro de 2016

Revista da Faculdade de Direito - UFPR, Curitiba, vol. 61, n. 1, jan./abr. 2016, p. 193 - 218 